\title{
EL PÉPLUM Y LA GONSTRUCGIÓN DE LA MEMORIA
}

\author{
Óscar Lapeña Marchena
}

Universidad de Cádiz

El cine ha servido como instrumento para administrar y reforzar los recuerdos del mundo occidental a lo largo y ancho del siglo XX; en la última década del siglo pasado, tras el final de la Guerra Fría, la rápida extensión de internet —sobre todo entre las generaciones más jóvenes-, cambia esta tendencia, ya que el fenómeno cinematográfico, tal y como se conoce hasta entonces, adquiere una nueva dimensión en la relación privada, anónima y supuestamente gratuita que el desarrollo de la red parece prometer y asegurar a sus usuarios e incondicionales.

A la hora de hablar de cine y de memoria histórica se tiende casi siempre a pensar en la memoria contemporánea de las sociedades occidentales, o en cómo nosotros - testigos de excepción del siglo XX-, recomponemos nuestros recuerdos con imágenes extraídas de noticiarios, documentales y también de películas de ficción. Pero igualmente podemos reflexionar acerca de cómo el cine ha modelado —y remodelado_, nuestra memoria más lejana, aquella que se remonta al Mundo Antiguo, o a lo que serían nuestras raíces culturales y políticas en cuanto a civilización mediterránea y occidental. En este caso en concreto, no se trata de pensar en qué medida aprovechar didáctica y académicamente los recursos cinematográficos que se ocupan de la historia y los relatos mitológicos de las sociedades de la Antigüedad, ni de dedicarse a la caza erudita del gazapo y del anacronismo histórico (Salvador Ventura, 2007:42). Queremos ir más allá y plantear una breve reflexión sobre cómo en Occidente el cine ha reescrito nuestros orígenes como civilización, y en especial cómo lo ha hecho un género definido y con unas características específicas: el péplum en el sentido más extenso del término.

En más de una oportunidad, Federico Fellini recordó cuando, siendo apenas un niño, asistió en el cine a la proyección de Maciste all'inferno (G. Brignone, 1925). La sesión se convirtió en una ceremonia de apertura a un mundo nuevo en donde las dimensiones de la realidad y la ilusión de las imágenes en movimiento acabaron por fundirse (Brunetta, 1996:21). Los recuerdos del director de Rimini no son exclusivos, generaciones de occidentales han aceptado como válida una determinada concepción de sus propias raíces culturales elaborada, fundamentalmente, por el cine. Y concibiendo el cine, sobre todo, como una industria de ocio y de propaganda, antes que como una aislada manifestación artística.

Cuando hablamos de cine sobre el Mundo Antiguo, nos referimos al género denominado péplum y entendido siempre en su acepción más amplia. Bajo este término se incluyen películas que desarrollan argumentos de ficción ambientados en la Antigüedad, episodios 
históricos, relatos mitológicos, viajes de personajes del Mundo Antiguo hacia el futuro o de personajes contemporáneos en dirección al pasado, y también modernas adaptaciones e interpretaciones de otras obras. El material sobre el que trabajan todas estas producciones —independientemente de su manera de abordarlo, y más allá de las barreras del rigor y de la calidad estrictamente cinematográfica-, es sencillamente el que compone la base cultural de la sociedad occidental. Pero la cuestión realmente importante es ver y analizar cómo, veinte siglos más tarde, una sociedad reelabora mediante un instrumento de la cultura popular -el cine-, un discurso fundacional que gira alrededor de sus propios orígenes, y cómo reescribe de nuevo, y a luz de los hechos contemporáneos, su listado de valores legitimados por la antigüedad y tradición de los mismos.

Ya hemos mencionado el carácter industrial del cine en general y del péplum en particular: se trata, en su mayor parte, de películas realizadas para un consumo extensivo, no orientadas hacia un estreno espectacular en las grandes capitales, salvo excepciones ${ }^{1}$, sino que, lejos de ello, son en su gran mayoría films con una vida comercial más extensa de lo habitual, que encontraban su idóneo canal de distribución —en el caso concreto del gran país productor del género, Italia-, en la periferia de las grandes ciudades industriales septentrionales, en cines de barrio y en salas parroquiales (oratorios), que albergaban a un público muy definido: los espectadores que venían desde el sur del país a trabajar en el norte industrializado, en donde encontraron —entre otras muchas cosas-, el cine como uno de los factores fundamentales de su tiempo de ocio. (Spinazzola, 1963:78). En estos circuitos de barrios, de pequeñas ciudades y de periferia de los grandes núcleos urbanos no importaba que las carteleras no ofrecieran los estrenos actuales, por lo que en ellos se podían proyectar títulos con algunos años de antigüedad que serían bien recibidos por la audiencia. Muchos de estos espectadores eran los actores de un fenómeno social, político y económico que va estrechamente unido a la extensión del péplum, nos referimos a la radical transformación que sufre Italia y que le hace pasar de ser un país eminentemente agrícola a convertirse en una potencia industrial (Della Casa, 2001:306). En Italia, además, este mismo público le volvió mayoritariamente la espalda al movimiento neorrealista - que consagró a la industria cinematográfica transalpina tras la Segunda Guerra Mundial-, y buscó refugio en géneros que le permitían evadirse de la realidad, en especial en el péplum, que actuaba como un auténtico «psicoanálisis de los pobres» (Paolella, 1965:1), y donde bajo la presunta inocencia de los argumentos, los espectadores recibían datos más o menos aislados o esporádicos que se referían a sus orígenes como cultura mediterránea.

Estas películas trasladaban a la audiencia a un idílico mundo preindustrial y prepolítico, habitado por héroes surgidos de las entrañas mismas de la naturaleza y que no se veían agobiados por los complejos problemas de participación política o de reivindicaciones laborales que asediaban a los espectadores'; se enfrentaban a un mundo sencillo de buenos y malos -claramente diferenciados en la pantalla_, y cuando surgían problemas, éstos se solucio-

1 Es el caso de la fiesta organizada por J. E. Levine el 20-III-1959 en el hotel Waldorff Astoria de Nueva York para celebrar el estreno norteamericano de Le Fatiche di Ercole (P. Francisici, Italia / Francia 1958). La fiesta suponía el momento culminante de un complejo montaje propagandístico. (Lucanio, 1994:12).

2 La primera labor heroica de Maciste en Cabiria (G. Pastrone, Italia 1914), podría ser contemplada como una manifestación de ludismo primario: el forzudo interrumpe la cadena de montaje que garantizaba el abastecimiento de niños destinados a ser consumidos/sacrificados en la caldera/alto horno/ del vientre del Dios Moloch. 
naban del modo más simple posible, utilizando los puños pero no la oratoria, sustituyendo el diálogo por el golpe seco del garrote. Eran héroes ajenos a todos los cambios sociales y culturales que estaban teniendo lugar en Occidente, sobre todo en referencia al nuevo papel de la mujer, que tras los dos grandes conflictos bélicos del siglo XX empezaba a exigir igualdad real y plenos derechos políticos. Frente a esta emergente realidad $-\mathrm{y}$ en cierto modo, negándola-, Hércules, Ursus o el renacido Maciste de los años sesenta sólo conocían y se relacionaban con hacendosas mujeres humildes con las que aspiraban a llevar una apacible vida doméstica (Spinazzola, 1963: 111), o con reinas de la lujuria y la seducción, con las que pasaban una breve temporada, sabedores de que al final estas «mantis religiosas» acabarían recibiendo su castigo, como sucede en Gli Amori di Ercole (C. L. Bragaglia, Italia / Francia 1960), en donde la reina de las Amazonas, Hipólita, tras disfrutar de un apasionado romance con Hércules, muere a manos de los terroríficos árboles vivientes en los que había convertido a sus antiguos amantes. De cualquier modo, e independientemente del camino que decidiera tomar, el héroe forzudo jamás aburría a su incondicional audiencia con una historia sentimental, sino que este aspecto sólo ocupaba un porcentaje mínimo de su tarea, monopolizada por aquello que el público demandaba, una sucesión de aventuras solucionadas gracias a su descomunal fuerza (Podda, 1968:63).

El erotismo generosamente mostrado por las pantallas y llegado directa y fundamentalmente desde Babilonia, Egipto y la pagana Roma, era ajeno a las cortapisas de la censura de la época, permisiva con las habituales exhibiciones tanto de cuerpos masculinos como femeninos, que constituyen un indudable emblema del péplum. Los baños, los combates, las torturas y el simple paso antes las cámaras de los héroes y de las heroínas del péplum ya componían, por sí solos, una pasarela de cuerpos semidesnudos, cubiertos de aceite o aparentemente ocultos bajo todo tipo de gasas y seductoras transparencias.

Los héroes de este género desarrollaban su vida y sus aventuras al margen de los hechos que rodeaban a la audiencia del péplum; habitaban una burbuja de seguridad material e ideológica ambicionada por muchos de sus espectadores. Al tiempo que ofrecían unos modelos de comportamiento y unos determinados ideales. El triunfo final del héroe es, a su vez, el triunfo de todos los espectadores que se han sentido identificados con él (Abruzzese, 1965:6). Generaciones de europeos han visto a Hércules encarnado en el montañoso cuerpo del culturista norteamericano Steve Reeves, y se han acostumbrado a un supuesto ideal de belleza física que identificaba a los Dioses Olímpicos y a los grandes personajes de la Antigüedad con los músculos contemporáneos nacidos en los gimnasios y con la inestimable ayuda de los anabolizantes. Ese mismo público ha seguido disfrutando con el discurso y la propaganda de Augusto que convertía a la reina helenística Cleopatra VII en el máximo exponente del exotismo, del lujo y de la amenaza oriental. (Prieto, 2000). Y del mismo modo, ha aceptado una cronología válida para la Antigüedad de celuloide en donde todos los acontecimientos aparecen vinculados de un modo u otro para confluir en la figura de Jesucristo ${ }^{3}$. La variante religiosa del péplum ha subrayado con insistencia la idea de la inevitabilidad de la conversión religiosa de Roma, mediante un proceso rápido, en donde el bosque de los mártires ocultaba a la figura de Cristo.

3 En Spartacus (S. Kubrick, 1960), una vez sofocada la revuelta, el gladiador lanza a Craso una arenga profética — He'll come back. And he'll be millions_, en donde se adivina o se profetiza la llegada de Cristo. 
Para entender en toda su dimensión a los héroes frugales del péplum, basta comparar a Hércules o a Ursus con los protagonistas del western europeo que sustituirá al péplum como género favorito de la audiencia popular. En el western europeo —en muchos casos elaborado por los mismos directores, actores y equipo técnico que realizaba péplum pero adoptando seudónimos norteamericanos-, los héroes son profundamente egoístas, sólo actúan por dinero - Per un pugno di dollari (1964), es el elocuente título del primer film de la trilogía de Sergio Leone-, luchan por satisfacer sus propios intereses, no conocen lealtades duraderas $y$, en muchos casos, ni siquiera poseen una identidad perfectamente definida (Miccichè, 1975:116; Pintus, 1980:62). La distancia, en cuanto a valores morales y modo de actuar, que separa a los dos prototipos heroicos es muy considerable.

El péplum también ha modelado una particular imagen de la civilización romana en la que los espectáculos públicos se muestran sólo como una manifestación deportiva de masas, son particularmente crueles y sirven, ante todo, para alejar a la población de la política y de la práctica efectiva del poder. Algo así como el opio de la plebe cortado y distribuido por las manos malvadas de los gobernantes de Roma. Y un Imperio, además, en donde los reyes absolutos del espectáculo son los gladiadores, ídolos románticos que se transforman en perfectas maquinarias adiestradas para matar cuando resuenan las pesadas trompas romanas. Es éste un mundo tutelado desde la tribuna presidencial del Anfiteatro Flavio, desde donde un anacrónico Nerón anticipado a los tiempos decide caprichosamente sobre la vida y la muerte de los que combaten en la arena. (Hopkins \& Beard, 2006:41). Porque estos films han convertido a la Antigüedad en un espectáculo constante, y a sus espectadores en los testigos anónimos, no del devenir histórico, sino de una serie de fotos fijas que la luz de las pantallas devuelve. Habría que plantearse si esas generaciones de occidentales han consumido argumentos e imágenes siendo conscientes de que les hablaban de sus orígenes y raíces o si, por el contrario, las han visto y aprehendido sólo como relatos de ficción, como un mero ejercicio de fantasía más o menos desbordada. Bajo el envoltorio de argumentos aparentemente infantiles, con claras influencias del cómic, el espectador del péplum ha recibido breves instantáneas de un legado histórico y mitológico que, culturalmente, le pertenece y del que forma parte. Hércules, aún reencarnado en la musculatura agreste de un culturista, o más tarde perfilado por el trazo nada inocente de los estudios Disney, sigue siendo el prototipo de héroe del Mundo Antiguo.

¿Qué buscaba el público del péplum en las películas? ¿Únicamente evadirse de la realidad circundante?, y ¿qué le ofrecía el género? ¿Sólo diversión o, tal vez, envuelto en el entretenimiento banal se podría encontrar una determinada ideología aplicada a la visión y al juicio que se emite sobe la Antigüedad? Qué duda cabe que toda película nos facilita una información valiosísima sobre el momento y el contexto de su realización. En el caso de la producción, a niveles industriales, del péplum, estas películas nos dejan ver cómo determinados episodios históricos contemporáneos se reflejaban en las vivencias cinematográficas de Hércules, César, la antigua Roma o el Egipto nilótico. Por ejemplo, la situación de algunos países europeos bajo el dominio de la Alemania nazi ${ }^{4}$, el miedo a la infiltración e influencia comunista en Occidente, la confianza en la tarea restauradora del

4 En Ercole alla conquista di Atlantide (V. Cottafavi, 1961), la guardia personal de la reina de la Atlántida viste uniformes negros que recuerdan a los de las SS nazis. Además, son rubios y tienen ojos azules, en una clara referencia a un supuesto ideal de belleza que podríamos denominar ario. 
amigo americano — presente en la mayor parte de películas protagonizadas por los héroes culturistas que solucionan mediante la violencia los problemas dinásticos y de legitimidad política de las impotentes comunidades civiles-, o la referencia a algunos cambios socioculturales contemporáneos, aunque sea en clave de comedia, como sucede, por ejemplo, en La Regina delle Amazzoni (V. Sala, 1960), en donde dos aventureros, con su modo de pensar y proceder «machista» se encuentran ante una comunidad de mujeres en donde los roles habituales están radicalmente alterados. Y todo se narra mediante un discurso político que repite una y otra vez el argumento de la usurpación, de la reposición del poder legítimo, de la necesidad del recurso a la violencia para resolver los conflictos y de la incapacidad de las comunidades civiles para solventar los problemas nacidos en su seno, lo que les empuja a aguardar, con paciencia hebrea, la llegada de los salvadores/héroes, directamente de más allá de sus fronteras, que desembarcan dispuestos a resolver cuantas injusticias e ilegalidades encuentran a su paso.

El péplum, por tanto, creó una nueva mitología, o si se prefiere, propició el nacimiento -a niveles de cultura popular y de masas-, de una neomitología de raíces e inspiración clásica y adaptada a las necesidades de los tiempos presentes (Gonzáles, 1990). Pero el péplum no limita su radio de acción a la mitología sino que, del mismo modo, realiza y difunde una suerte de historia rápida — siguiendo siempre la estela de dos o tres conceptos claros, que no claves, e inmediatos-, y aportando datos básicos sobre hechos y personajes del pasado, todo ello rodeado por un envoltorio atractivo y fácil de consumir (Lapeña, 2006: 714). Se trata, en definitiva, de una historia igualmente acondicionada a los mecanismos productivos de las sociedades occidentales contemporáneas y a los modelos de consumo de ocio de la cultura de masas.

A la vista de lo expuesto, hay que reivindicar sin complejos la valía del péplum como creador a nivel popular de una muy peculiar concepción de la Antigüedad, de algunos de sus episodios históricos y de sus relatos mitológicos. Un Mundo Antiguo recreado con los condicionantes del presente. Así pues, a lo largo de los años, el péplum ha acabado formando un corpus amplio y heterogéneo de películas en donde confluyen la revisión mitológica en clave de desbordada potencia muscular, los hechos históricos ofrecidos con rapidez y aparente eficacia, la añoranza religiosa de virtuosos tiempos pasados o los viajes espacio-temporales, tanto aquellos que van del hoy al ayer (generalmente narrados en clave de comedia y jugando con el anacronismo), y los que empezando en el pasado llegan al presente (como es el caso de la amenaza silenciosa de las momias egipcias que desde sus sarcófagos se asoman al siglo XX para sellar la venganza por las afrentas sufridas a manos de los arqueólogos, emblema ilustrado del colonialismo occidental).

El péplum ha sido capaz de constituir un discurso que, gracias a la repetición (de argumentos, de personajes, de estilo narrativo) ha acabado por disponer de una coherencia ante los ojos y el juicio de sus espectadores. El carácter industrial del péplum se da por la realización en cadena de las películas, los rodajes simultáneos de diferentes films de igual temática, las repeticiones, sin rubor alguno, de argumentos, de repartos, de equipos técnicos, de títulos y del propio modelo del protagonista: el héroe forzudo; pero también mediante la utilización de los mismos decorados, vestuario, calzado, armamento e, incluso, de las mismas imágenes (batallas, incendios, planos de la maqueta de Roma...), que se integraban en el montaje de las diversas producciones. Al margen de recurrir a algunos trucos cinematográficos, como que el personaje principal pierda momentáneamente la memoria: en el proceso de 
recuperación de su identidad se iban alternando en el metraje imágenes y escenas de otros films ya conocidos por la audiencia (Della Casa, 2001:307). Esta manera de trabajar no sólo afectaba al péplum, sino que se extendía además, al modo de realizar películas en la Italia de los años sesenta 5 .

Es por esto que, dentro del horizonte homogéneo del péplum, las obras realizadas con un sello más personal acaban reluciendo con un brillo propio. Es el caso de películas de Federico Fellini _Fellini-Satyricon (Italia/Francia 1969)_, Pier Paolo Pasolini —Edipo Re (Italia/Marruecos 1967)—, Michael Cacoyannis — The Trojan Women (UK/USA /Grecia 1971)_, o Lars Von Triers -Medea (Dinamarca, 1988)_, pero también de otros directores habitualmente considerados como meros artesanos —el caso más representativo es el de Pietro Francisci, creador de Le Fatiche di Ercole (Italia 1958)_, pero en realidad auténticos profesionales de la industria cinematográfica.

Como decíamos, el péplum transmite a su público la sensación de formar parte de una tradición y de un pasado común. Esto sucedió, por poner un ejemplo elocuente, en la Italia recién unificada de comienzos del siglo XX, cuando las grandes películas ambientadas en los tiempos del Imperio Romano, en las ciudades italianas del Renacimiento, o en los gloriosos años del Risorgimento ${ }^{6}$, contribuyeron a crear una identidad común y a extender entre los espectadores el orgullo de pertenecer a una antigua y todavía vigorosa cultura. (Codelli, 1971:53). Italia, como nación moderna, acababa de nacer, pero Italia, como cultura, tenía miles de años a sus espaldas; la nueva industria cinematográfica ayudó a consolidar este discurso y a difundirlo entre los nuevos sectores burgueses del país. En la Italia decimonónica ya la ópera y la novela histórica habían realizado esa tarea, y en cierto modo, el cine tomaba el relevo (Redi, 1999:84). La Antigüedad, así recibida, se convirtió en un instrumento de cohesión social y política.

Idéntico planteamiento quiso ser desarrollado, aunque fracasó en su intento, por la Italia fascista, heredera según su propia y abigarrada propaganda de los éxitos militares y de la labor civilizadora del Imperio Romano. Esta retórica se plasmó en las multitudinarias escenas de Scipione l'Africano (C. Gallone, 1937), barroca exhibición sin límites de los valores y de la iconografía fascista realizada a la mayor gloria del Duce, y rechazada por el público italiano que en taquilla le volvió la espalda, ya que se encontró ante un producto desfasado, concebido como las antiguas películas italianas realizadas en los años previos a la I Guerra Mundial, y articulado alrededor de largos discursos y de un completo catalogo de personajes virtuosos y graves que en ningún momento conectaron con los intereses de la audiencia (Gori, 1988:16).

Esta película dirigida por Carmine Gallone resulta paradigmática en cuanto a la presentación del Mundo Antiguo a través de los medios de comunicación de masas y, tam-

5 Así, por ejemplo, unos decorados habituales del péplum fueron, a su vez, utilizados para rodar un emblemático título de la ciencia ficción italiana, Terrore nello spazio (M. Bava, 1965) (Cozzi, 2001: 76).

6 Estas producciones propiciaron el nacimiento del largometraje (primero en Italia, luego en los Estados Unidos), al desarrollar argumentos provenientes de la tradición literaria occidental o bien se trataba de episodios históricos que exigían más tiempo para poder ser convenientemente desarrollados en la pantalla; además, favorecieron el nacimiento de unos edificios construidos exclusivamente para albergar las proyecciones cinematográficas, que ahora estaban dirigidas a un público más culto y con un poder adquisitivo también mayor. El largometraje, en definitiva, dignificó al cine — sobre todos ante los ojos de la crítica一, y evitó que se perpetuara como un simple espectáculo de barraca (Gevinson, 1988: 133). 
bién, por lo que se refiere a los condicionantes políticos del momento histórico en que se produce. Y no sólo por la evidente identificación que se realizaba entre el personaje del general Escipión y la figura del Duce. La prensa especializada de la época subrayaba las diferencias existentes entre Scipione l'Africano y otras películas realizadas en el período de esplendor mudo del péplum italiano de los años inmediatamente anteriores a la I Guerra Mundial. Títulos como La Caduta di Troia (P. L. Borgneto \& G. Pastrone, Italia 1910), Quo Vadis (E. Guazzóni, Italia 1912) o Cabiria (G. Pastrone, Italia 1914), fueron unánimemente alabados por la crítica, recibieron el beneplácito del público e influyeron de manera decisiva a la hora de abordar las producciones sobre el Mundo Antiguo en otros países, en especial en Estados Unidos, algunas de cuyas superproducciones de este periodo son claramente deudoras de los modelos italianos. La diferencia, recalcaba la prensa, radicaba en que mientras esos primeros títulos mostraban sólo la apariencia externa de Roma, Scipione l'Africano iba un paso más allá y expandía a través de las pantallas el verdadero espíritu de Roma, el de los ciudadanos, el de los virtuosos políticos de la República y el de los legionarios (Comin, 1937:31).

El cine, por lo tanto, no sería solamente la apariencia exterior del pasado, sino que profundizaba hasta la esencia de unos valores, los tomaba y los trasladaba hasta el presente para provocar la comunión cívica con el público. Al final de la acción, después de mostrar con todo detalle la indiscutible grandeza de Roma —la del pasado (los decorados), y la del presente (los elefantes, muestra viva de la capacidad de la Roma actual, o sea de la Italia fascista, de realizar con éxito una película de esas dimensiones)—, el heroico Escipión abandonaba el foro y la ciudad para retornar a sus propiedades y trabajar humildemente sus tierras en la compañía fiel de su familia. Se lanzaba así un mensaje de austeridad —moral, económica-, antes el progresivo alejamiento de la Italia de los años treinta de Europa y de Occidente. Escipión culminaba sus hazañas con una reivindicación activa de valores como la tradición, la familia o el trabajo. El general romano, mostrado desde esa óptica, recordaba a la imagen de Benito Musolini encabezando alguna de las numerosas batallas —la del trigo, la de la lira, la de la natalidad_, con las que el fascismo quiso articular la política italiana.

Como conclusión, el péplum no sólo ha ayudado a crear una memoria histórica común, al repetir de manera constante y meticulosa algunos episodios del Mundo Antiguo; sino que ha ido más allá, ya que acompaña la exposición de los hechos con la emisión de un juicio también constante (la idea de permanente decadencia del Mundo Antiguo, de la inevitabilidad de la conversión al cristianismo). La idea de historia que ha ofrecido el péplum a generaciones de espectadores potencia la visión heroica, la aportación decisiva de los grandes personajes y el papel de la providencia; preocupándose sólo de los hechos políticos, religiosos y militares y, salvo excepciones, ignorando los condicionantes sociales y económicos. Se trata, en definitiva, de una concepción de la historia con una fuerte carga ideológica y portadora de un mensaje que definiríamos como abiertamente reaccionario. Tal vez sea la causa de que, en la Italia de la década de los sesenta, la prensa conservadora manifestara una benévola tolerancia y simpatía hacia el péplum, mientras que los periódicos progresistas y la crítica cinematográfica especializada directamente lo ignoraba (Abruzzese, 1965: 4). ${ }^{7}$

7 Tendría que llegar la revista francesa Cahiers du Cinema para empezar a reivindicar la obra de algunos directores del péplum, como Riccardo Freda o Vittorio Cottafavi. 


\section{BIBLIOGRAFÍA}

ABRUZZESE, A. (1965), «Mito della violenza e pistole scariche», en Cinema 60, n 54, pp. 412.

BRUNETTA, G. P. (1996), «Padre Dante che sei nel cinema», CASADIO, G. (Ed.). Dante nel Cinema. Ravenna, 1996, pp. 21-28.

CODELLI, L. (1971), «Les debuts du cinema italien», Positif, n¹27, pp. 51- 56.

COMIN, J. (1937), «Ritorno di Roma sullo schermo», Lo Schermo, n 1, pp. 30-32.

COZZI, L. (2001), Mario Bava. I Mille volti della paura, Roma.

DELLA CASA, S. (2001), «L'estetica povera del péplum», DE VICENTI, G. (ed.), Storia del Cinema Italiano. X. 1960-1964. Roma, pp. 306-318.

GEVINSON, A. (1988), "La nascita del lungometraggio in America», CHERCHI USAI, P. \& CODELLI, L. (eds.), Sulla via di Hollywood, 1911-1920. Pordenone, pp. 132-155.

GONZÁLES, A. (1990), «La fresque et l'imposture. Le peplum: un genre cinématographique qui se débat entre Histoire et Imaginaire», Melanges Pierre Lévêque. Vol. 5, Paris, pp. 133-160.

GORI, M. (1988), Patria Diva. Firenze.

HOPKINS, K. \& BEARD, M. (2006), II Colosseo. La storia e il mito. Roma.

LAPEÑA, O. (2003), «La República Romana en el cine», XI Congreso de la Sociedad Española de Estudios Clásicos, Madrid, pp. 707-714.

LUCANIO, P. (1994), With fire and sword. Italian spectacle on American screens 1958- 1968. New York.

MICCICHË, L. (1975), Il Cinema Italiano degli Anni'60. Venecia.

PAOLELLA, D. (1965), "La psychanalyse du pavre», Midi Minuit Fantastique, n 12, pp. 1-8.

PINTUS, P. (1980), Storia e Film. Trent'anni di cinema italiano (1945-1975), Roma.

PODDA, P. (1998), Cagliari al cinema. Storie e ricordi del cinema a Cagliari dalle origini alla seconda guerra mondiale Cagliari.

PRIETO, A. (2000), «Cleopatra en la ficción: el cine», Stud. hist. $H^{a}$ antig. XVIII, pp. 143-176. REDI, R. (1999), I/ Cinema Muto (1896-1930), Roma.

SALVADOR VENTURA, F. (2007), "Biografía histórica y estética surrealista en el aula: Simón del Desierto de Luis Buñuel», Quaderns de Cine, n 1, pp. 37-46.

SPINAZZOLA, V. (1963), Film 1963. Milano. 